\title{
BINOCULARITY IN PRISM-REARED MONKEYS
}

\author{
M. L. J. CRAWFORD ${ }^{1}$, R. S. HARWERTH ${ }^{2}$, Y. M. CHINO ${ }^{2}$ and E. L. SMITH, III ${ }^{2}$ \\ Houston, Texas
}

\begin{abstract}
SUMMARY
Prismatic binocular dissociation in infant monkeys mimicked a concomitant squint. Within 3 weeks, the numbers of binocular neurons in the primary visual cortex were reduced by half and did not recover with up to 5 years of subsequent unrestricted binocular visual experience. The monkeys failed to show binocular summation for spatial contrast sensitivity tasks and were unable to utilise horizontal binocular disparities in random-dot stereograms - two indices of stereoblindness. Electrophysiological analysis of the $\mathrm{V} 1$ and $\mathrm{V} 2$ cortices showed a dramatic reduction in binocular neurons. Analysis of interocular spatial phase tuning functions showed a conspicuous loss of excitatory binocular drive in V1 neurons which was sufficient to account for many of the defects in binocular function.
\end{abstract}

It is akin to bringing coals to Newcastle to assert that circuits of binocular neurons of the visual cortex constitute the neurophysiological substrate for binocularity and the associated function of stereopsis. Since the beginning of written history, it has been known that somewhere in the brain the visual information coming from the two eyes must be united in order to have a single perception of the world, and that unified single perception was reduced in quality and sensitivity if one eye was lost or disabled. Wheatstone's ${ }^{1}$ historical demonstration that binocular viewing of identical flat images set at a slight horizontal disparity induced the perception of the depth equivalent to a real-life scene, set investigators on a course of speculation and search to find the locus in the brain where monocular union could take place; where binocular vision arises with the full-blown expression of stereopsis. Wiesel and $\mathrm{Hubel}^{2,3}$ gave the search enormous impetus with their benchmark work, not only by describing the phenomenon of binocular convergence but, more relevant for the

From: ${ }^{1}$ The Department of Ophthalmology \& Visual Science of The Medical School at Houston, and ${ }^{2}$ The College of Optometry, The University of Houston, Houston, Texas, USA.

Correspondence to: M.L.J. Crawford, 6420 Lamar Fleming, Houston, TX 77030, USA. Fax: +1-713-7924513. e-mail: jcrawfor@gsbs.gs.uth.tmc.edu. story to be presented here, by establishing that early abnormal visual experience played a role in determining cortical circuitry and binocular function. Contemporary research by Bela Julesz ${ }^{4,5}$ showed that horizontal disparities in the binocular view of random-dot stereograms were alone sufficient to induce not only the perception of depth but the vivid perception of form as well. Concurrently, clinicians began to incorporate the findings of basic research into their theory and practice in the clinic. ${ }^{6-8}$ In short, the confluence of these theoretical, empirical and clinical efforts comes down squarely on the binocular neurons of the visual cortex as the neural substrate underlying binocularity, the general term which subsumes the definition of stereopsis, the sensing of horizontal disparities leading to the appreciation of depth. $^{9-12}$

Having a basic interest in the role of early visual experience in moulding the function of the visual system in children, several years ago we began controlled studies modifying the quality of visual experience in infant monkeys to simulate the visual disorders commonly encountered in the paediatric clinic. $^{13-15}$ Among the methods employed, we put prisms before the eyes of infant monkeys to simulate the optical conditions attendant on concomitant strabismus. We devised a lightweight, padded helmet for holding base-in wedge prisms, with one prism rotated downward to create a condition of chronic diplopia. ${ }^{16-18}$ The helmet was put on the monkeys at different ages, from birth up to 4 months of age, and worn continuously for durations between 1 and 12 weeks. This rearing strategy was selected to deprive the binocular neurons of V1 cortex, present in monkeys at birth, ${ }^{19}$ of normal binocular stimulation during infancy, with the further aim of relating the numbers and functions of binocular neurons to the behavioural abilities of these young monkeys.

That such abnormal early visual experience is ruinous for cortical binocular neurons is illustrated in Fig. 1a (0 years, open bars) which shows the ocular dominance distribution obtained immediately at the end of the period of wearing the prisms. ${ }^{16}$ This eye- 


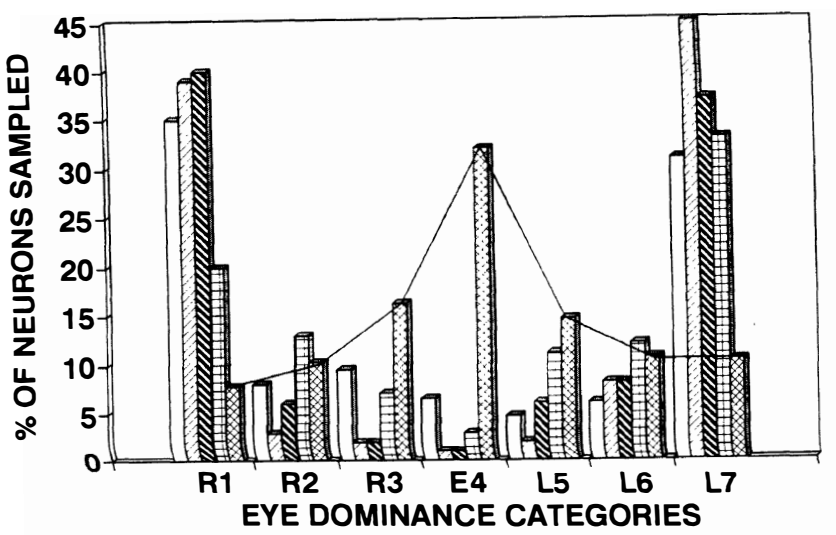

0 YEARS 5 YEARS

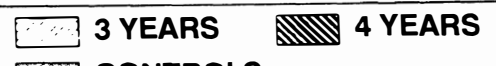
CONTROLS

(a)

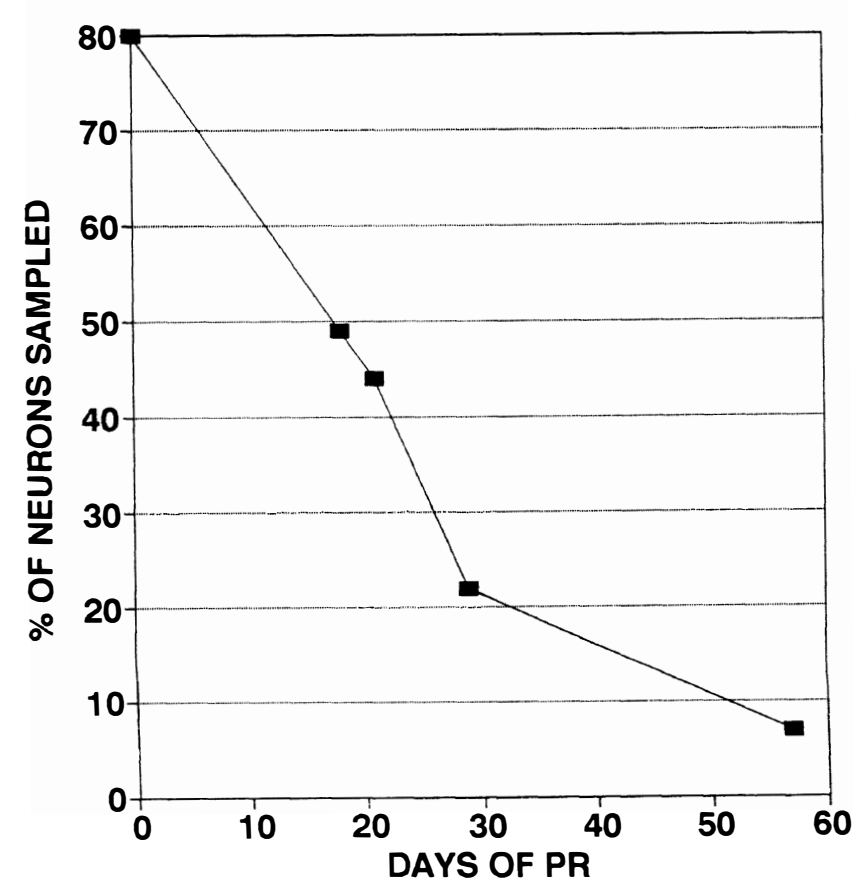

(b)

Fig. 1. (a) Eye dominance histograms for V1 neurons recorded from five groups of monkeys. Group 0 years was recorded immediately at the end of the period of prismatic binocular dissociation. Groups 3, 4 and 5 years were recorded after the indicated intervening period of post-treatment normal binocular experience. The histograms from the controls are connected by the continuous line to indicate the normally large numbers of binocular neurons, which are significantly reduced in all the prismreared groups. The right-eye dominant categories range from the monocular R1, to the weakly binocular R2, to the strongly binocular $R 3$ group. E4 represents the equally balanced and strongly binocular cells. The $L$ categories represent the neurons similarly dominated by the left eye. (b) The average relative percentage of remaining binocular $V 1$ neurons as a function of days of continuous prismrearing $(P R)$.
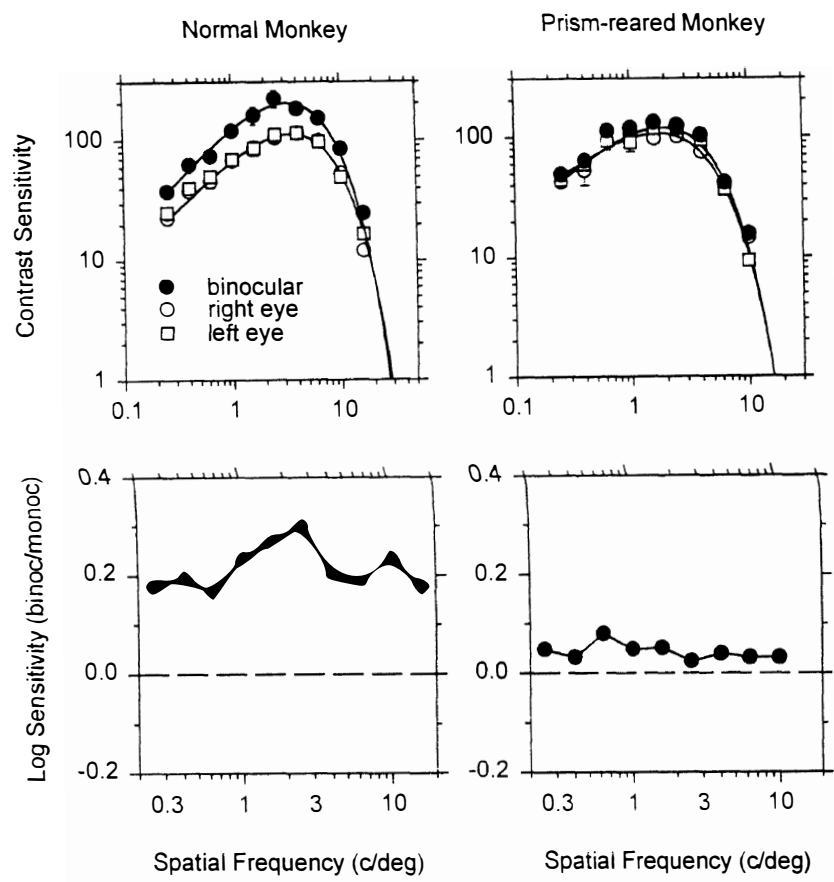

Fig. 2. Examples of monocular and binocular contrast sensitivity functions from a normal and from a prism-reared monkey.

dominance histogram shows that binocular neurons in V1 cortex are reduced by $60 \%$, and that this reduction occurs within a matter of days, being almost complete within 60 days (Fig. 1b). Note that the balance in the numbers of monocular neurons is retained, suggesting that the prism rearing procedure did not create an amblyopia in either eye.

Once lost, do binocular neurons recover their inputs when the prisms are removed? (The monkeys showed no evidence of strabismus.) Fig. 2 illustrates the contrast sensitivity functions of a normal and a prism-reared monkey. In the typical data set from a normal monkey of about 4 years of age, one can see that the monocular sensitivity for the two eyes is well balanced with peak sensitivities of about 4 cycles/deg, and a high spatial frequency cut-off of about 25-30 cycles/deg. Note that the binocular function is significantly higher than the monocular curves (about $0.2 \log$ units) at all spatial frequencies. This phenomenon of binocular summation is considered to reflect the contribution of the cortical binocular neurons to the monkey's superior binocular contrast sensitivity. ${ }^{20,21}$ In comparison, the curves to the right in Fig. 2 show that the prism-reared monkey gained no increase in sensitivity by binocular viewing compared with the best monocular curve, suggesting that there was no binocular advantage to sensitivity from viewing with two eyes. The absence of normal binocular summation suggests that binocular functions lost during the experimental treatment had not recovered, even with 2 years of subsequent binocular stimulation. $^{22}$ 


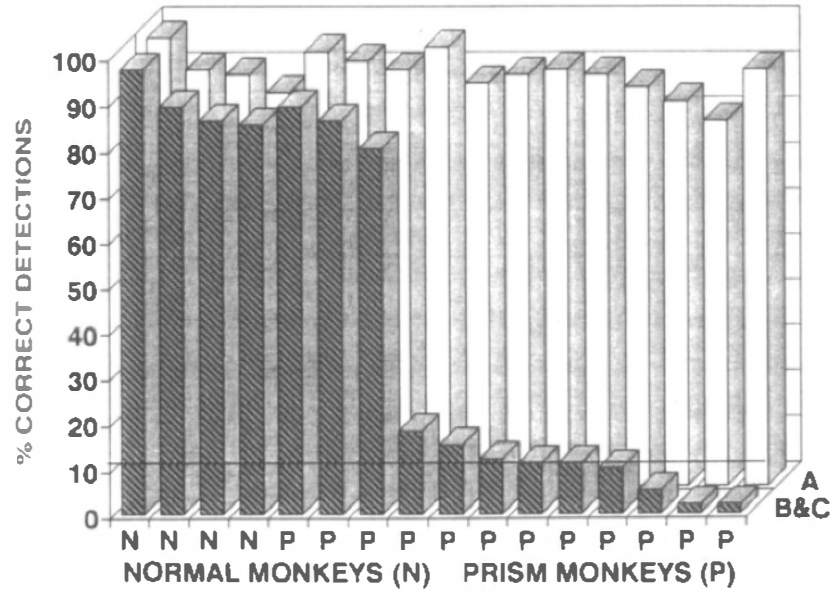

Fig. 3. Form detection $(A)$ and crossed and uncrossed disparity detection $(B \& C)$ in dynamic random-dot stereograms by 4 normal $(N)$ and 12 prism-reared $(P)$ monkeys. The horizontal line indicates chance performance in the task.

We next questioned the significance of the loss of binocular cells from the V1 cortex for functional stereopsis. Could these monkeys detect horizontal disparities, the universally accepted functional role of cortical binocular neurons? We tested these, and control monkeys, using random-dot stereograms, and found that indeed these prismatically dissociated monkeys were unable to use disparity cues in a behavioural task. The monkeys were trained to press and hold a lever while watching a colour video display for the appearance (or disappearance) of a stereoscopic form (a square, or a grating) embedded within a pattern of dynamic random dots, the form and apparent depth being determined by the horizontal disparity of a subset of dot-pairs. Fig. 3 summarises the performances of 4 normal and 12 experimental monkeys on a normally easy disparity detection task (15 min element disparity). The normal monkeys could readily detect the form from the disparities alone, while most of the experimental monkeys could not. This finding was consistent with the functional absence of binocular neurons in the visual cortex, ${ }^{16,22}$ and was interpreted as an indication of stereoblindness. Concurrently, we tested human subjects on the same apparatus and found that visually normal children could detect the disparities while those with histories of strabismus during infancy could not. ${ }^{23}$ These findings lent credence to our testing procedures, and suggested that similar defects in binocular cell function were likely to be present in the visual cortices of the children.

To relate the behavioural performance of the stereoblind monkeys to the loss of binocular neurons, we did electrophysiological studies in most of these monkeys and found essentially the same deficit in binocular neurons as we had found immediately after the prismatic treatment, i.e. the binocular neurons had not recovered after as much as 3 years of binocular stimulation. These data are shown in the eye-dominance histogram of Fig. 1a (3 years), which is virtually identical to histograms obtained immediately after binocular dissociation (0 years). Moreover, in another cohort of monkeys recorded 4 years following prism rearing (Fig. 1a; 4 years) there was still no significant recovery of binocular neurons. ${ }^{24}$

In a recent set of experiments on a subset of these stereoblind monkeys, we recorded not only the eyedominance profiles (Fig. 1a, 5 years; compare with Controls shown in this figure: there was no significant
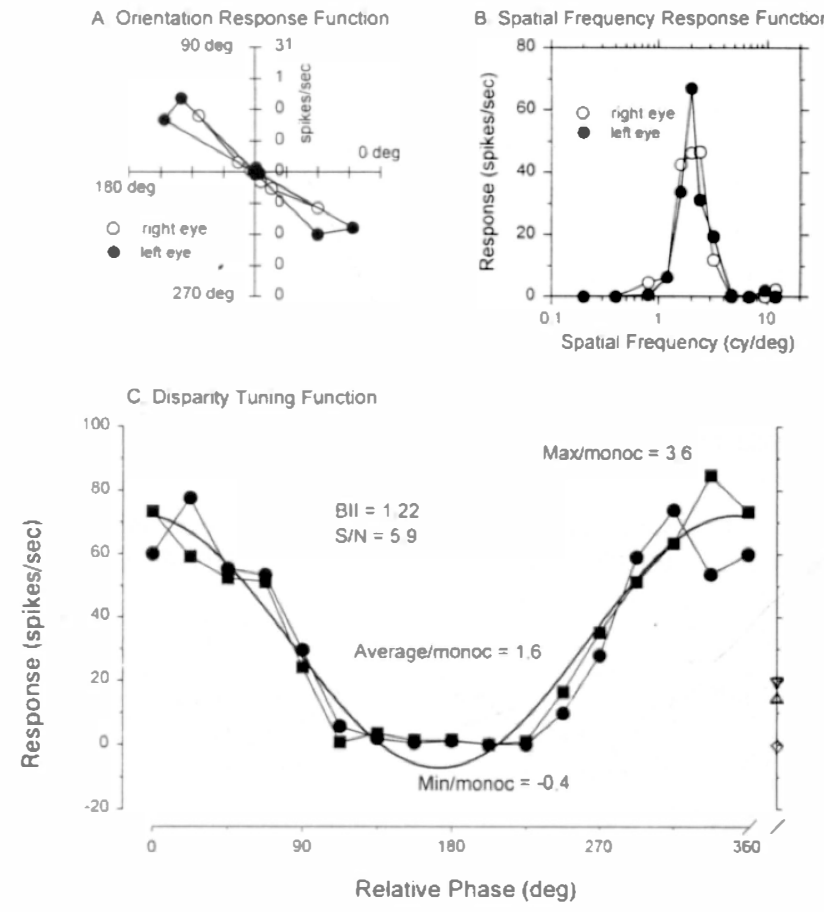

Fig. 4. Examples of the measurements made of simple and complex V1 neurons taken from control monkeys, and experimental monkeys some 5 years after prism-rearing. (A) Simple cell with narrow orientation tuning and balanced sensitivity. (B) Simple cell with binocularly matched narrow spatial frequency tuning. (Neither orientation nor spatial frequency tuning have been shown to be affected by prismrearing.) (C) Binocular spatial phase tuning for a simple VI neuron. Two sets of response data are shown, with a best-fit sine wave from which are derived indices of binocular interaction. The binocular interaction index $(B I I)=$ Amplitude of sine wave/Average binocular response. $S / N$ = Amplitude of the sine wave/the variance of the fit of the sine wave to the data. Max/monoc = Amplitude of sine wavelaverage monocular response rate. Average/monoc $=$ Average binocular response rate/average monocular response rate. Min/monoc $=$ Sine wave minimum/average monocular response rate. The average monocular response rates (triangles) for the left and right stimulations are shown on the ordinate to the right, along with the response rate when stimulated by a homogeneous field of space-averaged luminance equal to the gratings. This example of a simple V1 neuron shows a high degree of modulation by the drifting gratings, with a complete suppression of response when the gratings were in antiphase. 
recovery of binocular neurons), but in addition, the sensitivity of V1 neurons to the relative interocular spatial phase of optimal grating patterns. In our prior recordings we had used the traditional receptive field mapping techniques introduced by Hubel and Wiesel, mapping left- and right-eye receptive fields sequentially. With this method, any binocular interactions would have been missed. Therefore, we employed a methodology similar to that used by Ohzawa and Freeman ${ }^{25,26}$ on the cat, using dichoptic binocular stimulation of V1 neurons by drifting sine wave gratings. Fig. 4 illustrates the methods, showing in Fig. 4A a polar-coordinates plot of grating orientation tuning for a V1 neuron, indicating a narrow range of tuning around the $45 \times 225 \mathrm{deg}$ axis, with both receptive fields having the same orientation. Fig. 4B shows that this neuron had a narrow spatial frequency tuning around 2 cycles/deg, with the left eye being marginally more responsive. In general, neither stimulus orientation nor spatial frequency tuning were found to be substantially altered with prism-rearing.

Fig. 4C illustrates the analysis method for relative binocular disparity tuning and the results for a V1 simple cell. The neuron's response rate (spikes/s) is

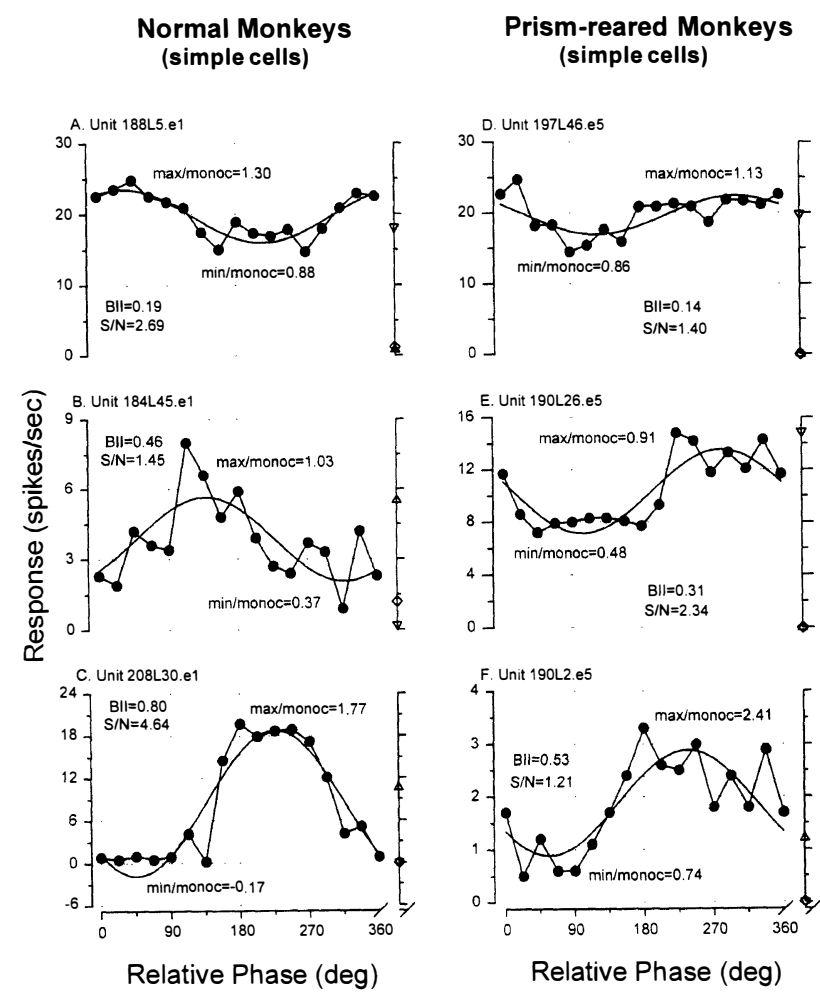

Fig. 5. Examples of the binocular spatial phase analysis of six simple cells drawn from the first quartile (top), from the median range (middle), and from the third quartile (bottom) of the BII distribution. Most simple cells were well modulated by the drifting gratings and showed $a$ binocular response facilitation at some spatial phase $(E$ shows a rare example of a response modulation, but suppressed below the best monocular response rate). shown as a function of the relative interocular spatial phase of the drifting gratings presented dichoptically at the optimal grating orientation, velocity and spatial frequency. The two sets of data, collected about 45 minutes apart, have been fitted by a sinusoid, using a least squares method. Symbols on the right-hand ordinate show the responses for independent monocular stimulation, as well as the maintained rate when the receptive field was stimulated by a uniform field comparable to the space-averaged luminance of the grating. This cell maintained a stable response over many hours, with clear binocular interactions characterised by binocular facilitation at one relative phase (0) and complete binocular suppression of the response when the spatial phase of the grating in one eye was shifted by about $180 \mathrm{deg}$. Five indices of binocular interaction are indicated on this figure: (1) the binocular interaction index (BII); ${ }^{25}$ the peak amplitude of the sine wave divided by the average binocular response, where a value of 0 indicates no binocular spatial phase interaction and a value of 1 indicates a high degree of interaction and complete suppression at non-optimal phases; (2) the signal-to-noise $(\mathrm{S} / \mathrm{N})$ ratio, the variance about the sine wave fitted to the data, (3) the ratio of the maximum binocular response divided by the maximum monocular response (Max/monoc); (4) the average binocular
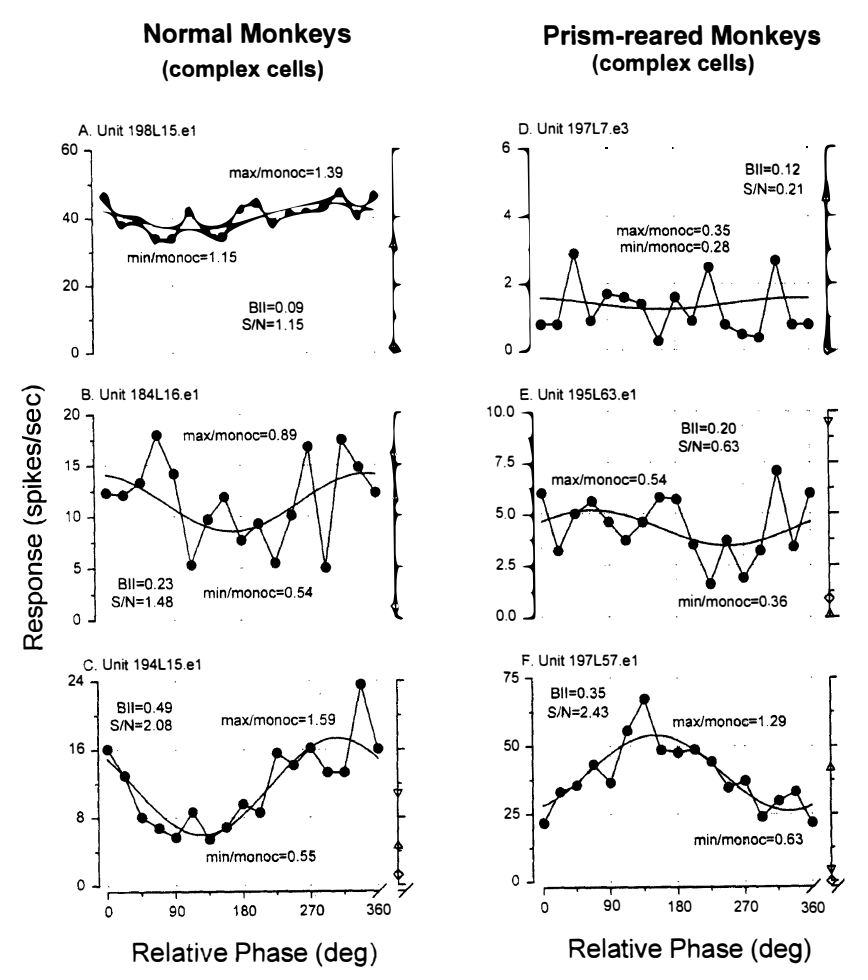

Fig. 6. Examples as in Fig. 4, but for similar samples from complex cells. Note that the response modulation is somewhat less than that for simple cells. $(D)$ and $(E)$ are examples of suppression of the binocular response below that of the best monocular response - more frequently found in the complex than in the simple cells. 
response divided by the best monocular response; and (5) the minimum binocular response divided by the minimum monocular response.

Figs. 5 and 6 present three samples each of simple and complex cells from normal and from the prismreared monkeys. The samples from top to bottom represent cells of increasing levels of spatial phase modulation: the top panel represents cells with relatively low levels of binocular interaction, typical of those within the first quartile of the BII distribution; those in the middle panel represent cells near the median of the BII distribution; and the bottom panel represents cells with high levels of binocular modulation from the third quartile of the BII distribution. The pattern of BII of the simple cells (Fig. 5) shows an overlapping range of binocular spatial phase interactions in both the normal and the prism-reared monkeys, with the BII being somewhat smaller in the middle and lower panels for the prismreared monkeys.

In a similar manner Fig. 6 compares the complex V1 neurons in the normal and the prism-reared monkeys. As was the case for the simple cells, the examples from the normal and the prism-reared monkeys show considerable overlap. A hint of what is to come in the overall group comparisons is seen in the upper-right panels, where suppression is evident in that the binocular modulation at all phase angles is significantly smaller than the best monocular modulation.

Comparisons of Figs. 5 and 6 suggest that complex neurons generally show less modulation to binocular stimulation than do simple cells, consonant with the findings in normal cats. ${ }^{26}$
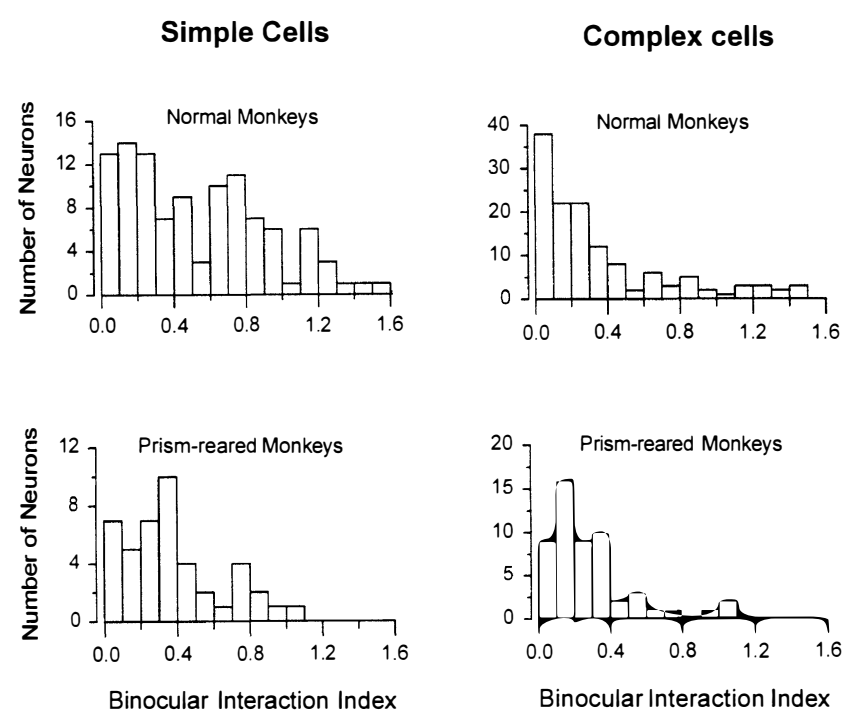

Fig. 7. Histograms of the simple and complex neuron categories shown for normal and prism-reared monkeys as a function of the binocular interaction index, BII. Note in the histograms from the prism-reared monkeys that both simple and complex cells with high BII values were found less frequently than normal.
Differences in the binocular V1 cell profiles for the normal and prism-reared monkeys become evident when the neuronal distributions are compared. Fig. 7 shows the distribution of the BII for the simple and complex cells from the normal and the prism-reared monkeys. Recalling that the BII ratio indicates the strength of the binocular spatial phase interaction $(0$ indicates no phase-specific binocular interaction, and a value of 1 indicates a high degree of interaction) it is seen that normally simple cells tend to have more of the high BII values. If one compares the numbers of simple cells having BII values greater than 0.6 (an arbitrary selection), the relative percentage for simple cells is twice ( $45 \%$ of the sample; $47 / 104)$ that for complex cells (21\% of the sample; $27 / 129)$. Prism-rearing has the effect of reducing the relative percentages of V1 neurons with high BII values by half $(20 \%(9 / 44)$, for the simple cells; $9 \%(5 / 54)$, for the complex cells). That is, V1 neurons best suited for discriminating binocular spatial phase differences are greatly reduced.

The binocular facilitation in excitation which comes from binocular stimulation is indicated in the ratio of the average binocular response divided by the average monocular response from the best eye, and is shown as a histogram in Fig. 8. Prism-reared monkeys show two feature differences in the distributions of both simple and complex neurons. Relative to the control animals, there are fewer neurons with high ratios (cells which show the highest excitatory facilitation) in the distributions of

\section{Simple Cells}
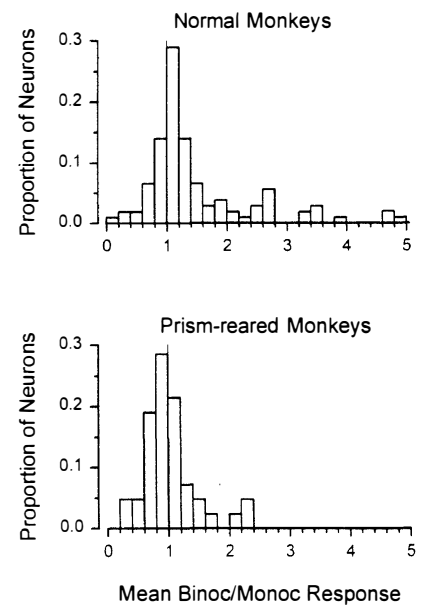

Complex Cells
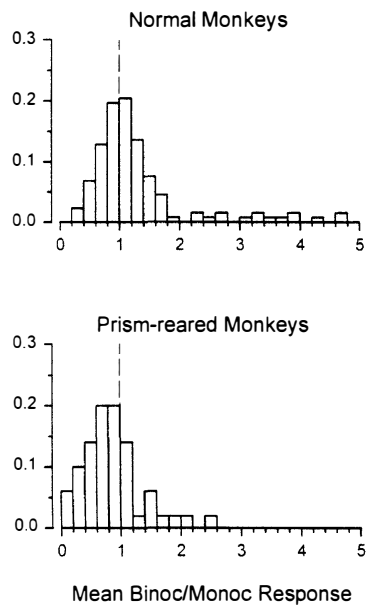

Fig. 8. Histograms of the simple and complex neuron categories shown for normal and prism-reared monkeys as a function of the ratio of best binocular/best monocular response rates. Note in the prism-reared monkeys that cells having the highest ratios are missing, i.e. of the remaining reduced population of binocular neurons, fewer than normal have high binocular facilitation rates. Concurrently, there are more neurons with ratios of less than 1, indicating a relative increase in neurons showing binocular suppression. 
both simple and complex cells. For example, of the simple cells from normal monkeys, $74 \%$ yielded ratios greater than 1 , many showing a three-fold response increase over the monocular response, yet in the prism-reared monkeys the percentage of cells was reduced to $41 \%$. A similar reduction is seen in the complex cells: $58 \%$ in normal monkeys compared with $30 \%$ in the prism-reared monkeys. Complementary to these reductions in binocular excitatory neurons, there was an increase in the proportion of V1 neurons having ratios less than unity, i.e. neurons showing binocular suppression. The distributions from normal monkeys show that $26 \%$ of the simple cells and $42 \%$ of the complex cells had mean ratios less than 1 . The prism-reared monkeys had almost double the numbers $(59 \%$ and $70 \%$, simple and complex cells, respectively) of cells with suppression ratios.

What conclusions may we draw from these experiments? Binocular neurons of V1 cortex, present at birth, are recruited and tuned by normal visual experience during infancy. Prism-rearing, as does a concomitant strabismus, constitutes an inhospitable stimulus environment for maintaining and developing the cortical circuitry essential for stereopsis. The consequence of this abnormal rearing condition is a relative: (1) loss of the sub-set of $\mathrm{V} 1$ neurons which have the highest binocular spatial phase sensitivity, (2) loss of the sub-set of facilitative binocular neurons - V1 neurons which could provide the greatest cooperative excitatory drive to higherorder visual cortex, (3) an increase in those binocular neurons showing suppression under binocular stimulation. These alterations in the V1 neuronal populations are manifest in the failure of primates so treated to be able to utilise horizontal disparity cues in support of stereopsis.

This research was supported in part by NIH grants, EY01120, NS19342, EY10608, and Research to Prevent Blindness.

Key words: Binocularity, Depth perception, Monkey vision, Stereopsis, Strabismus, Visual cortex.

\section{REFERENCES}

1. Wheatstone C. Contributions to the physiology of vision: on some remarkable, and hitherto unobserved, phenomena of binocular vision. Phil Trans R Soc Lond 1838;128:371-94.

2. Wiesel TN, Hubel DH. Single cell responses in striate cortex of kittens deprived of vision in one eye. $\mathbf{J}$ Neurophysiol 1963;26:1003-17.

3. Wiesel TN, Hubel DH. Comparison of the effects of unilateral and bilateral eye closure on cortical responses in kittens. J Neurophysiol 1965;28:1029-40.

4. Julesz B. Binocular depth perception with familiarity cues. Science 1964;145:356-62.

5. Julesz B. Foundations of cyclopean perception. Chicago: University of Chicago Press, 1971.
6. Von Noorden GK. Binocular vision and ocular motility: theory and management of strabismus. St Louis: CV Mosby, 1990.

7. Wright KW, Matsumoto E, Edelman PM. Binocular fusion and stereopsis associated with early surgery for monocular congenital cataracts. Arch Ophthalmol 1992;110:1607-9.

8. Gregg FM, Parks MM. Stereopsis after congenital monocular cataract extraction. Am J Ophthalmol 1992;114:314-7.

9. Marr D, Poggio T. Cooperative computation of stereo disparity. Science 1976;194:283-7.

10. Marr D. Vision. San Francisco: WH Freeman, 1982.

11. Blake R, Wilson HR. Neural models of stereoscopic vision. Trends Neurosci 1991;14:445-51.

12. Westheimer G. Seeing depth with two eyes: stereopsis. The Ferrier Lecture. Proc R Soc Lond B 1994;257: 205-14.

13. Crawford MLJ, Blake R, Cool SJ, Von Noorden GK. Physiological consequences of unilateral and bilateral eye closure in macaque monkeys: some further observations. Brain Res 1975;84:150-4.

14. Von Noorden GK, Crawford MLJ. Morphological and physiological changes in the monkey visual system after short-term lid suture. Invest Ophthalmol Vis Sci 1978;17:762-8.

15. Crawford MLJ, Von Noorden GK. The effects of short-term experimental strabismus on the visual system in Macaca mulatta. Invest Ophthalmol Vis Sci 1979;18:496-505.

16. Crawford MLJ, Von Noorden GK. Optically induced concomitant strabismus in monkeys. Invest Ophthalmol Vis Sci 1980;19:1105-9.

17. Smith EL, Harwerth RS, Crawford MLJ. Spatial contrast sensitivity deficits in monkeys produced by optically induced anisometropia. Invest Ophthalmol Vis Sci 1985;26:330-42.

18. Crawford MLJ. Optical control of early visual experience in monkeys. Behav Brain Res 1995 (in press).

19. Wiesel TN, Hubel DH. Ordered arrangement of orientation columns in monkeys lacking visual experience. J Comp Neurol 1974;158:307-18.

20. Campbell FW, Green DG. Monocular versus binocular visual acuity. Nature 1965;208:191-3.

21. Harwerth RS, Smith EL, Boltz RL, Crawford MLJ, Von Noorden GK. Behavioral studies of the effects of abnormal early visual experiencē in monkeys: spatial modulation sensitivity. Vision Res 1983;23:1501-10.

22. Crawford MLJ, Smith EL, Harwerth RS, Von Noorden GK. Stereoblind monkeys have few binocular cortical neurons. Invest Ophthalmol Vis Sci 1984;25:779-81.

23. Crawford MLJ, Von Noorden GK, Meharg LS, Rhodes JW, Harwerth RS, Smith EL, Miller DD. Binocular neurons and binocular function in monkeys and children. Invest Ophthalmol Vis Sci 1983;24:491-5.

24. Crawford MLJ, Pesch TW, Von Noorden GK. Excitatory binocular neurons are lost following prismatic binocular dissociation in infant monkeys. Behav Brain Res 1996 (in press).

25. Ohzawa O, Freeman RD. The binocular organization of simple cells in the cat's visual cortex. J Neurophysiol 1986;56:221-42.

26. Ohzawa O, Freeman RD. The binocular organization of complex cells in the cat's visual cortex. J Neurophysiol 1986;56:243-59. 